\title{
Smoother pebbles and the shoulders of giants: the developing foundations of information science
}

\author{
David Bawden ${ }^{1}$ \\ Department of Information Science, City University, London
}

\begin{abstract}
Some developments in the information science discipline over a period of thirty years are discussed, by selecting topics covered in the early issues of Journal of Information Science, and tracing their influence on subsequent developments, largely though by no means exclusively through JIS papers. Five main themes are covered: the information discipline per se; the foundations of that discipline; the nature of information; relations between discipline and profession; and education for information science. The continuing resonance of the writings of Farradane and Brookes are noted.
\end{abstract}

Keywords: information science; information history; journal of information science; information professions; education

\section{Introduction}

The Journal of Information Science (JIS) was first published in 1979, replacing The Information Scientist (TIS) which - though described as the 'Journal of the Institute of Information Scientists' - was not generally regarded as a true academic/professional journal. The intervening period of nearly thirty years, a time span commonly taken as equivalent to a 'generation', gives the opportunity to consider the issues covered in the early issues of JIS, to set them into the context of the development of the information science discipline over time, and to assess the significance of some of the main contributions and contributors.

This is done by focusing on some of the articles and editorials published in the first two volumes of JIS, covering the years 1979 and 1980, tracing some of the preceding treatment of the issues, and following later developments, particularly - though not exclusively - through the pages of TIS and JIS. The set of literature cited is selected to show the origins and development of the issues, and is in no way intended to be comprehensive.

The discussion is focused around five main, albeit overlapping, themes. An initial consideration of the information science discipline itself leads fairly naturally to thoughts on the foundations of the discipline, and

${ }^{I}$ Correspondence to: David Bawden, Department of Information Science, City University, London, ECIV OHB. Email: dbawden@soi.city.ac.uk 


\section{David Bawden}

that in turn to the central question of the nature of information. There follows a consideration of the relation between discipline and profession, and in particular the role of research, and the closely associated question of the most appropriate form of education for information science. As we shall see, all of these themes are represented in the first issues of JIS, and all have remained 'live' topics ${ }^{2}$ to the present day.

\section{The Information Science discipline}

The emergence of an information science discipline was recognised, albeit with the caveats and uncertainties which have bedevilled discussions ever since, by Alan Gilchrist, the first editor of JIS, in an editorial on the first page of the first issue of the first volume of the new journal. Gilchrist [1] wrote tentatively:

“.. a profession, and possibly a science or discipline, is being increasingly recognised..."

and more definitely

"If there is such a discipline as information science (and we believe there is) then it is time that an international consensus was established as to its definitions and the area in which it should fruitfully be applied".

The cynic might say that we are still waiting for this, nearly thirty years later.

The nature of the subject had, of course, been discussed previously (and rather inconclusively), particularly in the pages of JIS's predecessor. For example, Saunders [2] argued that, although the field had originated with scientific information, its methods were equally applicable to other subject areas. Farradane [3] urged that a "true information science' should be a science in its own right, an "academic and applied study" and "not an applied multidisciplinary art"; this would require an application of rigorous scientific method, and a careful reexamination of basic concepts. He developed this view of information science modelled on the physical sciences, and based on experimental studies of carefully defined physical information entities in two subsequent papers $[4,5]$.

As noted below, Brookes [6] developed a somewhat similar view of information science, on the basis of a much more detailed analysis of the foundations of the subject. There was "a very important role for a science of information, a role as yet unclaimed by any other discipline, and which is a logical and natural extension of the interests and activities of those who currently claim to be information scientists". Like Farradane, Brookes attempted to envisage information science by analogy with the physical sciences, based on quantitative analysis of objective and publicly observable phenomena. Unlike Farradane, he regarded its central concept of interest, information, as a non-physical entity.

A different, and with hindsight perhaps more realistic, view of the nature of the discipline, though the lens of a prediction of the future was made by Charles Meadow [7] in the fourth issue of JIS. Meadow, like several authors in JIS papers at that period, looked to the year 2001 to consider the status of information science and scientists. He considered three groups: information science practitioners; information system designers; and information scientists per se. His predictions in general seem rather more prescient than most others of the time, given the dangers of any such attempt (Bawden [8]). He foresaw that most information would be available online and fully searchable, and that "almost all people, in whatever area, will be more conscious of the existence of information systems", although, like all commentators of the time, he saw this in terms of professional and educational activities; no-one imagined the Internet, the home computer, or social networking. His view of the future information practitioner, and the organisations in which they work, was that primarily of a

2 It was noted that when the Journal of Documentation recently reprinted a series of classic papers, chosen by currently active experts, the late 1960s and early 1970s was chosen as a particularly significant time for innovations in information research. It seems that the same may be true of the late 70 s and early 80 s for conceptual thinking on the discipline. It is intriguing to speculate on the reasons for both. 


\section{David Bawden}

counsellor/advisor. His vision here has come to pass to some extent, though - again like most other commentators - he exaggerated the imminent death of the book, and the capability of machines to act as search assistants.

His vision for the 'science of information' is rather less definitive than others of the time - Farradane for one - and with hindsight may seem more realistic. "There is not really much of a science of information today", Meadow wrote, "but this, I believe, will change significantly by 2001 ". However, his vision of this future information science was that of an "integrating science", since information is of concern to many other disciplines: he named computer science, mathematics, economics, psychology, electrical engineering, communication theory, linguistics, sociology, and others. The distinction is not in content, but in outlook: information science will focus on human behaviour, of both groups and individuals, in interacting with information and the systems which deliver it. Therefore:

"information science .. may never evolve into a body of knowledge and methodology distinguishable from other sciences .. [it] will be concerned with the integration of the contributions of other sciences, much as ecologists are today ... [there is] evidence that information science will remain only an integrating science, never a basic one". [I have to say I do not understand the "only" in the last sentence. It seems an unnecessary self-belittling expression.]

This idea of the 'integrating science' seems a compelling one today, after nearly three decades of seeing information science try, and fail, to claim particular areas of expertise or practice as its own, from online searching to text retrieval to internet portal creation. As Jack Meadows [9] points out information science seems to be more sensitive than other disciplines about exchanges with other areas.

Various ideas have been put forward as to how the information science discipline may be understood: Webber [10] summarises a variety, and two more recent examples are given by Zins [11] and by Zhang and Benjamin [12]. Several have followed Meadow's general approach, of regarding it as a multidisciplinary or interdisciplinary area, focusing on the concept of information or some aspect of it, as two examples almost thirty years apart will show:

"an interdisciplinary science that investigates the properties and behaviour of information, the forces that govern the flow and use of information, and the techniques, both manual and mechanical, of processing information for optimal storage, retrieval and dissemination" (Borko [13])

"a multidisciplinary field of study, involving several forms of knowledge, given coherence by a focus on the central concept of human, recorded information, and underpinning several practical disciplines" (Bawden [14])

The idea of information science as a borrowing or integrating science has attractions, apart from its seeming to be realistic: but against this must be set the viewpoint that a constant input of ideas, and people, from other disciplines may mitigate against the development of a cohesiveness, and consequent lack of an ability to develop any specifically information science theory base (Robertson [15], Weller and Haider [16]). Conversely, while we may like to find evidence that information science ideas, and people, filter into and enrich other disciplines, "such expansions of our horizons make no sense unless we have some academically coherent core which relates the disparate activities" (Robertson [15]).

It would be wrong to conclude this section without acknowledging that some commentators in the early twenty-first century held the view that the optimism about the developing discipline which was exhibited by the writers in the early JIS has proved ill-founded: that, as Webber ([10]) reports it

“..the sapling which Farradane and Brookes had such hopes for in 1980 has, unnoticed by many, shot up, but become tangled in the undergrowth of more robust disciplines and is now weakened, perhaps beyond saving".

I certainly do not accept such a view. On the contrary, I have argued (Bawden $[14,17])$ that the validity and strength of the information science discipline may only show itself in the future, by the adoption of concepts from that discipline by the physical and biological sciences, in contrast to the usual 'intellectual flow'. This would be a more fundamental adoption of concepts and perspectives, rather than a more superficial adoption of techniques 


\section{David Bawden}

and algorithms, as in the chemoinformatics and bioinformatics specialisms. I think that the JIS writers of 1980 would like that idea.

\section{Foundations of the discipline}

Considering the significant number of papers written over the years dealing with information science as a discipline and profession, there have been relatively few attempts to spell out in detail what the foundations, or underlying philosophical or conceptual bases, of such a discipline might be.

One such attempt, arguably the most ambitious to date, was provided by Bertie Brookes, in a series of four papers in the first three issues of JIS, preceded by his 1976 article in TIS. The first, and arguably most fundamental, deals with "philosophical aspects" (Brookes [18]). It argues for Popper's 'three worlds' ontology as a suitable foundation for the discipline, and presents a 'fundamental equation' for information science: an approach very much in line with Farradane's desire for an equivalence with the physical sciences, and building on Brookes' earlier thought (Brookes [19]). The next two papers (Brookes [20, 21]) deal with quantitative aspects: mainly with the need for rank-frequency statistics and "logarithmic laws" in analysing social, including informational matters, and in providing a mathematical description of information spaces, again building on earlier studies by Brookes ([22, 23, 24]). The final paper in the series (Brookes [6]) discusses the "changing paradigm" of information science. In this, Brookes brings together the arguments of the previous three papers, to show, both in outline and in specifics, what an information science based on his ideas would be like. The specifics are essentially those of bibliometric analysis, of the use of rank-frequency logarithmic plots to analyse any example of the communication of information, and of the construction of concept maps based on these. In more abstract disciplinary terms, Brookes claims that his four papers, in showing the need for a science of information noted above, also show that such a science would be based on several foundational principles:

- its main role would be "the exploration and organisation of Popper's World III of objective knowledge"

- it would be scientific, in that all the data studied would be "publicly observable and the whole approach objective"

- it would require a recognition that information and knowledge were not physical, but "extra-physical entities which exist only in cognitive (mental or information) spaces"

- quantitative analysis would be paramount, using techniques from the physical sciences, adapted to cognitive spaces

Brookes' series of papers has been highly influential and widely cited, and continues to be cited to the present day, with varying degrees of attention given over time to their different aspects: for an assessment on his influence, see a biography and bibliography in an issue of JIS dedicated to him (Shaw [25]).

His bibliometric principles have been generally accepted into the mainstream, particularly his emphasis on methods based on measurement of ranks rather than sizes (Tague-Sutcliffe [26]). Nonetheless, the situation described by Shaw in 1990 [25] is still the case: his early bibliometric works are still more highly cited in total than his philosophical propositions.

$\mathrm{He}$ is generally accepted as the originator of the highly influential 'cognitive approach' to information science, and to information retrieval in particular (Ingwersen and Järvelin [27]) ${ }^{3}$. Belkin [28] wrote that

"not only was he one of the earliest proponents of this view, but he personally influenced many of those others who have also espoused it... he is one of those who have succeeded in using the

3 Ingwersen and Järvelin remind us that De Mey was the first to use the term, although Brookes had already outlined the characteristics of the approach. 


\section{David Bawden}

cognitive view to develop a strong and influential theory for information science. Although this is only one facet of Brookes' contribution to information science, it is a significant one."

Brookes' proposal of Popper's three worlds ontology as a suitable philosophical basis for information science, however, is arguably his most distinctive, and certainly longest lasting, contribution, since, as noted above, his bibliometric writings, though initially highly cited, have now been 'absorbed' into the mainstream, and are not so strongly associated with his name . [Central to Popper's analysis of objective, i.e. communicable, knowledge is the idea of three 'worlds': World 1 of physical items - books, computers etc.; World 2 of subjective mental state and 'personal knowledge'; and World 3 of communicable information - 'the 'contents' of books, databases, etc.] Whilst others (for example Swanson [29]) independently commended the relevance of Popper's epistemology to librarianship and information science, Brookes made it the basis of a well-developed meta-theory. Neill [30] who provided a critical and detailed, though generally supportive, analysis of Brookes' series of papers, soon after their publication, in agreeing that

"there is a very real place for Popper's philosophy in library and information science" and that

"Brookes has been very astute in recognising the relevance of Popper to information science. Indeed, it is not for his logarithmic law of information that he [i.e. Brookes] will be remembered, but for this discovery of Popper's three worlds. When Brookes teaches quantitative methods, it is his discussion of Popper that excites the students, not his logarithms: for Popper's is clearly a working epistemology for librarians and for information scientists".

It seems that Neill was correct, for Brookes' views have been widely cited and generally supported (see, for example, Neill [31], Abbott [32], Abbott [33], Bawden [34], Spink and Cole [35], Ingwersen and Järvelin [27], and Zins [11]), though some have dissented (see, for example Rudd [36] and Capurro [37]), and some have used the concepts of information spaces and Popper's worlds without reference to Brookes (see, for example, Boisot [38]).

It is perhaps ironic that the validity and value of Popper's three worlds viewpoint have gained greater acceptance in the information science area than in philosophy itself. As Notturno [39], a proponent of Popperian viewpoints, puts it:

"many contemporary philosophers regard World 3 as an unfortunate product of Popper's old age: as incoherent, irrelevant and perhaps, if the truth be told, a bit ridiculous".

It would be nice to think mere information scientists have something to teach the philosophers.

In the first paper of Brookes' series, alongside his Popperian viewpoint, and intrinsically connected to it, was presented his 'fundamental equation of information science'. This widely quoted equation takes the form:

$$
\mathrm{K}[\mathrm{S}]+\Delta \mathrm{I}=\mathrm{K}[\mathrm{S}+\Delta \mathrm{S}]
$$

A knowledge structure $\mathrm{K}[\mathrm{S}]$ is changed by the addition of an increment of information $\Delta \mathrm{I}$ to a new knowledge structure, the change in structure denoted by $\Delta \mathrm{S}$. Brookes noted that this equation stated only in general terms; the terms are ill-defined, and dependent upon one another, so that the equation cannot be used for calculation or prediction. But it is central to the cognitive approach to information science, and Brookes argued that the interpretation of this fundamental equation was the basic research task of information science.

Although this equation has been much quoted, relatively little has been achieved in applying it in any practical way, or even in understanding it better. Todd [40] has proposed how this might be done, and examples have been given by Cole [41] and Todd [42] For the most part, however, the equation remains as a rather reproachful reminder of how far we are from fulfilling Brookes' research programme.

It is notable that there has been no other example of such an ambitious attempt to set out the foundations of the subject since Brookes' series of papers. Perhaps the nearest is Hjørland's socio-cognitive theoretical perspective, with its associated domain analysis approaches providing an understanding of the unique competences of information scientists (Hjørland [43, 44, 45]). 


\section{David Bawden}

\section{The nature of information}

The first issue of JIS included an article by Jason Farradane [4] in which he set out a definition of 'information' which could form the basis for a 'true science of information', based on ideas alluded to in his earlier TIS paper (Farradane [3]). This pair of papers may be considered the first to discuss in detail the nature of information as understood in information science, although Wersig and Neveling [46] had outlined a variety of possible ways of understanding the term, and Belkin [47] almost simultaneously presented alternative views.

Farradane's view was that information must be understood as a physical thing: "any physical form of representation, or surrogate, of knowledge, or of a particular thought, used for communication". (In this, he forshadows the now commonly made distinction between knowledge as the personal and subjective understanding possessed by individuals, and information as the objective means by which it is communicated.) This, for Faradane, is the only sort of understanding of information which can support the development of information as an "experimental science". He eschews philosophical speculation and mathematical modelling; what matters is the obtaining of experimental data for analysis and predication, echoing the concepts and methods of the physical sciences. Farradane's ideas and their practical consequences have been developed in detail by Davenport [48], among others.

As noted above, Brookes [6] took a very different view of information, arguing that it was not physical, but existing only in cognitive space, which he identified with Popper's World III of objective knowledge. For Brookes, information was "fragmented knowledge", while knowledge was "coherent structures of information".

In these early JIS papers, we already see the genesis of two principal models (using the term in its most general form, to mean a simple picturing of concepts to aid understanding) which have been used to explain the distinction between information and knowledge. Farradane's view, noted above, of information as a communicable surrogate for knowledge points to a view of knowledge as the personal and subjective understanding possessed by individuals, and information as the objective means by which it is communicated (see, for example, Orna and Pettitt [49]). Brooke's view of knowledge and information as essentially the same 'essence', distinguished by the degree of coherence, points to the commonly quoted 'information hierarchy', with data-information-knowledge-wisdom arranged on a line, or in the form of a pyramid, sometimes with other elements such as 'capta' ('interesting data') added (see, for example, Checkland and Holwell [50] and Rowley [51]).

Despite this early elucidation of two helpful ways of understanding the concept of information, there has subsequently been little agreement on the best way of defining or explaining it with any precision: an unfortunate state of affairs, given the necessity, as noted by Farradane, for such a definition to act as a basis for the explication of the discipline (see, for example, Meadow and Yuan [52], Bawden [53], Cornelius [54], Capuro [55], and Floridi [56]).

A current point at issue strikes an interesting echo from the past. As noted earlier in this paper, one approach to the nature of information sees information as intrinsically physical, or at least having roots as an entity in the physical universe (see, for example, Stonier [57], Bates [58, 59], and Bawden [14, 17]). The other sees it as nonphysical, a purely human and socially constructed entity (see, for example, Hjørland [62]). It may not be too fanciful to see the origins of both in the early JIS debates, the former following Farradane's insistence on the basically physical nature of information, the latter drawing largely from Brookes' cognitive stance.

\section{Relation between discipline and profession}

The relation between discipline and profession, and - almost equivalently - between theory (or research) and practice, has been a difficult issue for as long as long as either has existed.

Farradane's disapproval of a "multidisciplinary art", and corresponding approval of an academic discipline, has already been noted. Brookes [63], in the same issue of TIS, gave a more positive assessment, drawing an analogy with the industrial revolution. The scientific laws of thermodynamics were only elucidated many years 


\section{David Bawden}

after steam engines were in widespread use: similarly, the laws of information science may emerge only after the practice of information handling is well developed. Meadows [9] makes a similar point that:

".. the simplest picture is to see information science as a wide-ranging subject in which various sectors develop a theoretical foundation, as and when they are ready to do so".

All these authors are very clear that a theoretical basis for the discipline should emerge at some point.

Brookes' analogy was referred to by Gilchrist [1] in the first JIS editorial, who argued that there should be a:

"clear connection" between theory and practice, and that not only were practical applications worth discussing in themselves, but that "the 'science' will be advanced by rigorous examination and analysis of the practice".

Sadly, this positive vision has not been fully realised: it has been more common to find information researchers criticising practitioners for failing to value research, and practitioners charging researchers with conducting studies of little relevance to practice. This controversy appeared clearly in the second volume of JIS, with Stephen Robertson [64] suggesting that book reviews in a previous issue had:

"betray[ed] a feeling that much previous and present [information retrieval] research is misdirected or irrelevant ... This feeling seems to me to be quite widespread in the profession, and I regret that good and useful research work may be ignored as a result".

The argument has continued ever since, despite goodwill on both sides: see, for example, Blick [65], Webber [10], Haddow and Klobbas [66], McNicol [67] and Weller and Haider [16].

Gilchrist's first editorial also emphasised the idea that information technology should never be paramount in the professions: the study of users and their needs, and of the social and organisational roles of information should be emphasised. This has been a continual, and understandable theme throughout the decades since. The last issues of TIS and the first of JIS carried a number of articles and letters dealing with a major concern of the day: the relative effectiveness and cost-effectiveness of searching printed indexes and computerised files. The proceedings of the London International Online Information Meetings for 1979 and 1980 show some other main concerns of the day: again, the relative merits of online and 'manual' searching; whether, and how, to train 'end users'; new technologies such as teletex, videodiscs, 'non-bibliographic' databases, and minicomputers; the possible uses of computer graphics; the exciting possibility of every library having a computer, and what might be done with it; and so on. Even for those of us who were there, it is difficult to remember what some of these issues were about; for a new generation, it will be impossible to imagine that it was seriously suggested that the nature of the discipline and profession could be dictated by them. Yet the same happened with the more recent technologies mentioned above, and is happening again with Web 2.0 and social networking. The only antidote is a disciplinary core of basic - perhaps theoretical is the wrong word - concepts, invariant to technology changes, so that it will be easier to evaluate and exploit whatever new technologies may emerge; exactly as Alan Gilchrist told us in 1979.

When speaking of 'profession', in this context, it is not always clear what is meant. At the time of the establishment of JIS, there was a very clear information science profession in the United Kingdom, with its own Institute, and an equivalent in the USA with its own Society. Since that time, both have lost their unique identity albeit in different ways: in the UK by a merger with the librarians to form CILIP, and in the USA by the explicit incorporation of information technology, to form ASIS\&T [10]. Whether it is still meaningful to speak of an information science profession is therefore a moot point. However, this is not as new a situation as it might seem: Gilchrist [1] spoke of the new JIS serving "allied fields", such as the management and communication sciences, and today we could name many other allied fields. It seems a remarkable waste of time and effort to worry about setting up disciplinary boundaries, and debating who is in and who is out. I have suggested [14] that it is feasible to make a distinction, on theoretical grounds from a Popperian analysis, between information science per se, dealing with individual information behaviour seeking and use, and related 'collection sciences' - librarianship, records management, etc. [It may not be too far-fetched to see in this an echo of an informally stated distinction, made many years ago: "the information scientist is primarily a scientist who is approaching the literature and other sources of information from the research standpoint, while the librarian, even though he may have studied science, is trained to approach the literature from the standpoint of a custodian" (Dyson and Farradane [68]). 


\section{David Bawden}

The important matter is to create and disseminate a body of information science theory and principles, to inform reflective practice in all the professional activities centred around information. I believe this to be the natural extension of the work of the JIS pioneers, in the changed environment of today.

\section{Education for information science}

The subject of the appropriate form of education for the new discipline of information science was discussed in a paper in the first issue of JIS (Simpson [69]). This is largely a detailed description of the origins of information courses at UK universities, and hence mainly of historical interest, but some issues still have resonance today. Simpson notes that information science at its outset was almost entirely concerned with the handling of scientific information, and courses were therefore largely involved with specific training for this work, sometimes with the inclusion of the study of scientific subjects included ${ }^{4}$. Hence the focus in the earliest curriculum for information science education: "The emphasis of the syllabus throughout is that the information scientist is primarily a scientist and will obtain, organise, and disseminate information from the standpoint of one as well versed as may be possible in knowledge of the subjects dealt with" (Dyson and Farradane [68]).

However, a broadening, under the influence of commentators such as Saunders (noted above) was already underway. He also notes that some early courses in information science had "emphasis placed on information science as a science of information, and not simply a question of information of science". This revisits questions of the intrinsic nature of the discipline noted above. Simpson also raised a question still being discussed today, when he stated that "postgraduate courses in information science seem to have a greater chance of success [than undergraduate courses]"; a point later re-emphasised by Bottle [70].

He emphasised the then important role of the Institute of Information Scientists in specifying the 'Criteria for Information Science', essentially the required content of any information science course; for the origins of the Criteria, see Dyson and Farradane [68]), for later development, see Oppenheim [71], and for a review of their context, see McGarry [72]. Six topics were regarded as essential, at the time Simpson wrote: knowledge and its communication; sources of information; organisation of information; retrieval of information; dissemination of information; and management of information. Six others topics were regarded as of value: data processing; research methods; mathematics; linguistics; foreign languages; and advanced information theory and practice. The core topics still have a remarkably current feel, perhaps with data processing, which would now be described as IT applications, promoted to the core, at the expense of the editorial and document reproduction aspects of dissemination. The 'of value' topics, with the exception of research methods, are now too peripheral - and perhaps too demanding - to be accepted as a part of modern information education. The criteria were later modified several times, largely in the ways suggested above, before being absorbed, on the demise of the IIS into the "virtually equivalent" CILIP criteria (Webber [10]).

There continues to be much debate about the appropriate curriculum for 'library and information studies' or 'library and information management'; these being the two most usual terms for the subject area encompassing information science, and within which curriculum discussions tend to take place ${ }^{5}$. The report of a recent European curriculum development project shows the variety of views and the wide spread of subjects and their treatment in the current curriculum (Kajberg and Lørring [73]), as do the papers in an Educational Forum at the 2007 CoLIS conference (Bawden [60]). The issues raised have a familiar ring: is there a 'core' of material for the subject, or at

4 I can recall being asked at my first job interview whether I thought of myself as an 'information scientist' or a 'scientific informationist', a residuum of this distinction.

5 The Department of Information Science at City University London runs a Masters course in Information Science. The names of the department and course have remained unchanged since their inception; the only case in the UK for which either is the case. 


\section{David Bawden}

least a list of recommended topics, from which a curriculum might be constructed?; what should be the central 'mode of thought' for library/information education?; what is the best balance between research-based and theoretical material, and skills-based and practical issues? [and one is here reminded of Brookes' [74] concern that information should not be regarded as "a collection of practical skills without underlying theoretical coherence"]; what are the appropriate links with other subject areas?; what are the relative merits of specialised and generalist courses ?; and what is the appropriate balance between first degree and postgraduate study in this area ? [as noted above, an issue long debated]. All of these topics were being discussed in the early issues of JIS, and it is difficult to know whether it is comforting or disconcerting to see them still live issues; accompanied, of course, by newer concerns, such as the validity of the I-School concept, and the place of Web 2.0 in information education (Bawden, Robinson, Anderson, Bates, Rutkauskiene, and Vilar [75]),

The question of a 'core' for information science education is closely associated with the idea of the discipline itself, for the educational 'core' must surely comprise those topics which are both central and unique to the discipline. As we have seen, there has been little agreement on the exact nature of the discipline, or even whether it exists, and accordingly some commentators doubt whether the concept of core is a useful one (see, for example, Raju [76]). There does, however, seem to be a reasonably consistent view through time. In 1986, Gilchrist [77] argued that the unique set of skills of the information scientist relied on knowledge and understanding of: information sources, particularly formal ones; needs and behaviour of users of information; knowledge structures, including epistemology, classification and retrieval languages; formulation of objectives and appropriate organizational structures. Twenty years on, it has been argued that information seeking and information retrieval, including relevant aspects of human information behaviour and also including information resources and knowledge organisation, may form the realistic core of information education (Bawden [61]). These topics approximate to the first three of Gilchrist's topics, showing a remarkable stability over time, and suggesting that this idea may have some validity. The last of Gilchrist's topics approximates to the 'information management' area, which tends to be necessarily rather mutable and contingent on circumstances and technologies of the time (Wilson [78]). This stability over time is noted by Jack Meadows in an article in this issue [79], in which he notes that there is greater agreement on what information scientists should study than on how information science should be defined.

\section{Conclusions}

"Brookes", wrote Stephen Robertson in 1990, "had .. a vision of a discipline of information science, on the edges of which we have been hovering for a good 20 years" [15]. Perhaps we are still hovering there.

It is all too easy in reflecting on the significance of past events or writings to make facile or false analogies: to say that things are 'the same', while the seeming similarity is actually superficial, or due to a change in the way that terms are used. This risk must be acknowledged in an article such as this, which draws attention to apparent similarities between issues, views and visions of thirty years ago, and those of the present day. I believe, however, that these similarities are real: that the insights of Brookes, Farradane and other writers of the late 1970s and early 1980s are still valid, and they raised issues which are still relevant, and problems which are still to be solved.

This is not to suggest that no progress has been made, which would indeed be a dismal view. This article has focused on foundations, concepts and philosophies, and these are notoriously slow to change, and tend to see the same issues re-emerging over time. A focus on the technical and operational issues within information science would have seen a different story told; of problems solved, confusions clarified, systems designed and built, and so on, though not necessarily associated with the information science "brand". As Meadows puts it "the information science activities developed over the past 50 years have triumphed, but information science as a separate entity may be on the wane" [79].

Nor is the story of the discipline and profession a negative one. Both have survived (despite some predictions during the early JIS years that they would not), despite the totally unanticipated changed in networked ICTs which have brought the information and its communication to the forefront of professional, social, and economic life in a way which could not have been conceived thirty years ago. That, in itself, is no mean achievement. 


\section{David Bawden}

As a result, much - arguably far too much - of the time of both academic and practising information scientists has had to be spent simply coping with the practical consequences of change, rather than reflecting on fundamentals, and reconsidering the discipline's foundations. It has at least helped to verify that it is essential to focus on basic information principles and on invariant issues of information behaviour, rather than being sucked into a concentration of the details of the technology de jour. As a result, we have not fully worked through the insights of the founders of the discipline, let alone replaced them with entirely new insights. Or, to put it more positively, of the newer theories and concepts which have been developed - and they are many - those which have built directly on the insights of the Brookes-Farradane generation have had most impact, and seem to have the potential to be developed further.

Perhaps most excitingly, we are now in a situation where the concept of information has entered the vocabulary of the physical and biological sciences, as a fundamental concept in an entirely novel way. I have suggested (Bawden $[14,17]$ ) that this may be a unique opportunity for the insights of information science to be 'exported' to these other disciplines. This may be seen as a more positive prospect than a continued search for more 'information science substance'. For those in the information science discipline who came to it from the natural sciences - Farradane and Brookes among many others, including myself - it would surely be a exciting prospect $^{6}$.

\section{References}

[1] A. Gilchrist, Editorial, Journal of Information Science, 1(1) (1979) 1-2

[2] W.L. Saunders, The nature of information science, The Information Scientist, 8(2) (1974) 57-70

[3] J. Farradane, Towards a true information science, The Information Scientist, 10(3) (1976) 91-101

[4] J. Farradane, The nature of information, Journal of Information Science, 1(1) (1979) 13-17

[5] J. Farradane, Knowledge, information and information science, Journal of Information Science, 2(2) (1980) 75-80

[6] B.C. Brookes, The foundations of information science. Part IV. Information science: the changing paradigm, Journal of Information Science, 3(1) (1981)3-12

[7] C.T. Meadow, Information science and scientists in 2001, Journal of Information Science, 1(4) (1979) 214 222

[8] D. Bawden, The nature of prediction and the information future: Arthur C Clarke's Odyssey vision, Aslib Proceedings, 49(3) (1997) 57-60

[9] A.J. Meadows, Theory in information science, Journal of Information Science, 16(1) (1990) 59-63

[10] S. Webber, Information science in 2003: a critique, Journal of Information Science, 29(4) (2003) 311-330

[11] C. Zins, Redefining information science: from "information science" to "knowledge science", Journal of Documentation, 62(4) (2006) 447-461

[12] P. Zhang, and R.I. Benjamin, Understanding information related fields: a conceptual framework, Journal of the American Society for Information Science and Technology, 58(13) (2007) 1934-1947

[13] H. Borko, Information science: what is it ?, American Documentation, 19(1) (1968) 3-5

6 They would also recognise the references to pebbles and giants in the title as taken from the writings of Sir Isaac Newton: "If I have seen further, it is by standing on the shoulders of giants" and "I do not know what I may appear to the world, but to myself I seem to have been only like a boy playing on the sea-shore, and diverting myself in now and then finding a smoother pebble or a prettier shell than ordinary, while the great ocean of truth lay all undiscovered before me." 


\section{David Bawden}

[14] D. Bawden, Organised complexity, meaning and understanding: an approach to a unified view of information for information science, Aslib Proceedings, 59(4/5) (2007) 307-327

[15] S.E. Robertson, B.C. Brookes and information science education: a personal note, Journal of Information Science, 16(1) (1990) 9-10

[16] T. Weller, and J. Haider, Where do we go from here? An opinion on the future of LIS as an academic discipline in the UK, Aslib Proceedings, 59(4/5) (2007) 475-482

[17] D. Bawden, Information as self-organised complexity: a unifying viewpoint, Information Research, (2007) 12(4), paper colis31, available from http://informationr.net/ir/12-4/colis/colis31.html $\quad$ Accessed $20^{\text {th }}$ December 2007)

[18] B.C. Brookes, The foundations of information science: Part I. Philosophical aspects, Journal of Information Science, 2(3/4) (1980) 125-133

[19] B.C.Brookes, Robert Fairthorne and the scope of information science, Journal of Documentation, 30(2) (1974) 139-152

[20] B.C. Brookes, The foundations of information science: Part II. Quantitative aspects: classes of things and the challenge of human individuality, Journal of Information Science, 2(5) (1980) 209-221

[21] B.C. Brookes, The foundations of information science. Part III. Quantitative aspects: objective maps and subjective landscapes, Journal of Information Science, 2(6) (1980) 269-275

[22] B.C. Brookes, The growth, utility and obsolescence of scientific periodical literature, Journal of Documentation, 26(4) (1970) 282-294

[23] B.C. Brookes, Theories of the Bradford law, Journal of Documentation, 33(3) (1977) 180-209

[24] B.C.Brookes, Measurement in information space: objective and subjective metrical spaces, Journal of the American Society for Information Science, 31(4) (1980) 248-255

[25] A. Shaw, B.C. Brookes and the development of information science: a bibliography, Journal of Information Science, 16(1) (1990) 3-7

[26] J. Tague-Sutcliffe, , Quantitative methods in documentation, in Fifty years of information progress: a Journal of Documentation review, London: Aslib, (1994) 147-188

[27] P. Ingwersen, and K. Järvelin, The Turn: Integration of information seeking and retrieval in context, Dordrecht: Springer (2005)

[28] N.J. Belkin, The cognitive viewpoint in information science, Journal of Information Science, 16(1) (1990) 11-15

[29] D.R. Swanson, Libraries and the growth of knowledge, Library Quarterly, 50(1) (1980) 112-134

[30] S.D. Neill, Brookes, Popper and objective knowledge, Journal of Information Science, 4(1) (1982) 33-39

[31] S.D. Neill, The dilemma of the subjective, Journal of Documentation, 43(3) (1987) 193-211

[32] R. Abbott, Information transfer and cognitive mismatch: a Popperian model for studies of public understanding, Journal of Information Science, 23(2) (1997) 129-137

[33] R. Abbott, Subjectivity as a concern for information science: a Popperian perspective, Journal of Information Science, 30(2) (2004) 95-106

[34] D. Bawden, The three worlds of health information, Journal of Information Science, 28(1) (2002) 51-62

[35] A. Spink and C. Cole A human information behavior approach to a philosophy of information, Library Trends, 52(3) (2004) 617-628

[36] D. Rudd, Do we really need World III? Information science with or without Popper, Journal of Information Science, 7(3) (1983) 99-105

[37] R. Capurro, What is information science for? A philosophical reflection, in Conceptions of library and information science, P Vakkari and B Cronin (eds.), London: Taylor Graham, (1992) 82-96 


\section{David Bawden}

[38] M.H. Boisot, Information space, London: Routledge (1995)

[39] M.A. Notturno, Science and the open society: the future of Karl Popper's philosophy, Budapest: Central European University Press (2000)

[40] R.J. Todd, Back to our beginnings: information utilization, Bertram Brookes and the fundamental equation of information science, Information Processing and Management, 35(6) (1999) 851-870

[41] C. Cole, Calculating the information content of an information process for a domain expert using Shannon's mathematical theory of communication: a preliminary analysis, Information Processing and Management, 33(6) (1997) 715-726

[42] R.J. Todd, Utilization of heroin information by adolescent girls in Australia: a cognitive analysis, Journal of the American Society for Information Science, 50(1) (1999B) 10-23

[43] B. Hjørland, Theory and meta-theory of information science: a new interpretation, Journal of Documentation, 54(5) (1998) 606-621

[44] B. Hjørland, Epistemology and the socio-cognitive perspective in information science, Journal of the American Society for Information Science and Technology, 53(4) (2002) 257-270

[45] B. Hjørland, Domain analysis in information science: eleven approaches - traditional as well as innovative, Journal of Documentation, 58(4) (2002) 422-462

[46] G. Wersig, and U. Neveling, The phenomena of interest to information science, The information Scientist, 9(4) (1975) 127-140

[47] N. Belkin, Information concepts for information science, Journal of Documentation, 34(1) (1978) 55-58

[48] E. Davenport, What do we look at when we do information science?, in Conceptions of library and information science, P Vakkari and B Cronin (eds.), London: Taylor Graham, (1992) 286-298

[49] E. Orna, and C. Pettitt, Information management in museums (2 ${ }^{\text {nd }}$ edn.), Aldershot: Gower (1998)

[50] P. Checkland and S. Holwell, Information, systems and information systems - making sense of the field, Chichester: Wiley (1998)

[51] J. Rowley, The wisdom hierarchy: representations of the DIKW hierarchy, Journal of Information Science, 33(2) (2007) 163-180

[52] C.T. Meadow, and W. Yuan, Measuring the impact of information: defining the concepts, Information Processing and Management, 33(6) (1997) 697-714

[53] D. Bawden, The shifting terminologies of information, Aslib Proceedings, 53(3) (2001) 93-98

[54] I. Cornelius, Theorising information for information science, Annual Review of Information Science and Technology, 36 (2002) 393-425

[55] R. Capurro, , The concept of information, Annual Review of Information Science and Technology, 37 (2003) 343-411

[56] L. Floridi, Two approaches to the philosophy of information, Minds and Machines, (2003) 459-469

[57] T. Stonier, Towards a new theory of information, Journal of Information Science, 17(5) (1991) 257-263

[58] M.J. Bates, Information and knowledge: an evolutionary framework, Information Research, 10(4) (2005) paper 239, available from http://informationr.net/ir/10-4/paper239.html (Accessed 20th December 2007)

[59] M.J. Bates, Fundamental forms of information, Journal of the American Society for Information Science and Technology, 57(8) (2006) 1033-1045

[60] D. Bawden, Facing the educational future, Information Research, 12(4) (2007), paper colise01, available from http://informationr.net/ir/12-4/colis/colise01.html (Accessed 20th December 2007)

[61] D. Bawden, Information seeking and information retrieval: the core of the information curriculum?, Journal of Education for Library and Information Science, 48(2) (2007) 125-138 


\section{David Bawden}

[62] B. Hjorland, Information: objective or subjective/situational ?,Journal of the American Society for Information Science and Technology, 58(10) (2007) 1448-1456

[63] B.C. Brookes, A new paradigm for information science, The Information Scientist, 10(3) (1976) 103-112

[64] S. Robertson, The value of research, Journal of Information Science, 2(2) (1980) 116

[65] A.R. Blick, Information science research versus the practitioner, Nachrichten fur Dokumentation, 34(6) (1983) 261-265

[66] G. Haddow, and J.E. Klobbas, Communication of research to practice in library and information science, Library and Information Science Research, 26(1) (2004) 29-43

[67] S. McNicol, Is research an untapped resource in the library and information profession?, Journal of Librarianship and Information Science, 36(3) (2004) 119-126

[68] G.M. Dyson, and J.E.L. Farradane, Education in information work: the syllabus and present curriculum of the Institute of Information Scientists Ltd., Journal of Chemical Documentation, 2(2) (1962) 74-76, reprinted in Journal of Information Science, 2002, 28(1) (1962) 79-81

[69] I.S. Simpson, Education for information science. 1. The United Kingdom, Journal of Information Science, 1(1) (1979) 49-58

[70] R.T. Bottle, Education for IS or IT. Is there a difference?, Journal of Information Science, 8(4) (1984) $167-$ 170

[71] C. Oppenheim, The Institute's new criteria for information science, Journal of Information Science, 4(5), (1982) 229-234

[72] K. McGarry, Education for librarianship and information science - a retrospect and revaluation, Journal of Documentation, 39(2) (1983) 95-122

[73] L. Kajberg, and L. Lørring, European curriculum reflections on library and information science education, Copenhagen: Royal School of Library and Information Science (2005)

[74] B.C. Brookes, Personal transferable skills for the modern information professional, Journal of Information Science, 15(2) (1989) 115-117

[75] D. Bawden, L. Robinson, T. Anderson, J. Bates, U. Rutkauskiene and P. Vilar, Towards Curriculum 2.0: library / information education for a Web 2.0 world, Library and Information Research, vol. 31, issue 99 (2007), pages to be added

[76] J. Raju, The "core" in library and/or information science education and training, Education for Information, 21(4) (2003) 229-242

[77] A. Gilchrist, What the information scientist has to offer, Journal of Information Science, 12(6) (1986) 273280

[78] T. Wilson, Towards an information management curriculum, Journal of Information Science, 15(4/5) (1989) 203-209

[79] J. Meadows, Fifty years of UK research in information science, Journal of Information Science, 34(4) (2008) pages to be added 